\title{
4. Hype, argumentation, and scientific dissemination
}

\author{
Adam Auch
}

Vasterman, Peter (ed.), From Media Hype to Twitter Storm. News Explosions and Their Impact on Issues, Crises, and Public Opinion. Amsterdam University Press, 2018

DOI: $10.5117 / 9789462982178 / \mathrm{CHO} 4$

\begin{abstract}
In this chapter, I examine the worry that media hype about scientific findings risks undermining public trust in science. Using the example of the seemingly exaggerated media coverage of a recent research finding concerning the effects of global climate change on the habitability of cities in the Middle East, I argue that making sense of this worry requires us to take seriously the value judgements involved in calling such coverage 'hype'. I argue that it is judgements of credibility (who and what one ought to believe) that are put into crisis by science hype and consider a few possible approaches to resolving this crisis.
\end{abstract}

Keywords: hype, credibility, trust, science journalism, philosophy of science

\section{Case study: Burning hell}

In October 2015, a pair of climate scientists, Jeremy Pal and Elfatih Eltahir, published a short paper in the journal Nature: Climate Change. In the paper, the authors use climate models for the region surrounding the Persian Gulf to make predictions about when a particular threshold for human survival might be exceeded for the first time. In particular, the authors predict that by the year 2100, heat events will occur in the region in which the 'wet-bulb' temperature (the combination of temperature and humidity) will exceed the point at which human beings are able to survive out of doors. In order to meet the threshold, wet-bulb temperatures of thirty-five degrees Celsius or more would need to be sustained for at least six hours, and would need to affect even those in shaded and well-ventilated spaces. Heat events of this 
kind would not be an everyday occurrence, but the authors predict they may occur several times over a thirty-year period. ${ }^{2}$ Although such events would be fatal for anyone caught outside, those with access to artificial cooling systems (such as central air-conditioning) would likely survive. Furthermore, the authors take pains to note that the predicted events can be avoided if significant action is taken in the present to reduce greenhouse gas emissions.

In conjunction with the publication of the academic paper, the public relations department of the Massachusetts Institute of Technology (where Eltahir is a professor of engineering) published a press release that summarized the main findings of the study in non-technical language. ${ }^{3}$ The authors worked closely with the author of the press release to ensure that it accurately reflected the nature and implications of their findings. ${ }^{4}$ Later the same day, the information in the press release was reported in a number of stories and blog posts by a wide variety of media outlets. The coverage was intense, with each outlet covering the research from a different angle, reflected in the headlines chosen to accompany the stories. The New York Times went with the relatively straightforward 'Deadly heat is forecast in Persian Gulf by $2100,{ }^{5}$ while The Washington Post chose the slightly more provocative headline 'Persian Gulf may be too hot for human survival by 2090. Here's what this means for your city.' ${ }^{6}$ Other headlines pushed the envelope even further. The website for Time magazine introduced its story with the headline "These cities may soon be uninhabitable thanks to climate change. ${ }^{7}$ But the most striking headline may have been that employed by the website of the Discovery Channel, ${ }^{8}$ which published its story under the heading 'Burning hell coming for Mideast deserts'. ${ }^{9}$

The stories were widely read and circulated freely on social media. Although the stories themselves adopted a more nuanced tone than the headlines, most of the pieces presented apocalyptic narratives in which climate change would force whole cities to be abandoned to the desert, with relatively little attention paid to the fact that the authors of the paper consider such scenarios a) unlikely and b) avoidable if action is taken to curb greenhouse gas emissions.

In a post for the current affairs website Slate, Eric Holthaus, the site's weather and climate blogger, faults the coverage for distorting the import of the research and potentially producing a state of despair and motivational inertia in readers. ${ }^{10}$ Holthaus argues that by exaggerating the severity of the predicted event (recall that the heat events would be serious, but survivable by those who remained indoors) while neglecting the important information that the predicted events were avoidable, the coverage risks leaving many readers with the mistaken impression that the study presaged an inevitable 
apocalypse. Instead of motivating readers to take action on blunting the effects of anthropogenic climate change, Holthaus worries the coverage has made it more likely that readers will throw up their hands, believing there is nothing to be done. In another post from October 2015, this time lamenting media coverage of retreating Antarctic glaciers, Holthaus puts the point in the following way: 'But lost in all the hype is an important message: It's not too late to save a really, really huge proportion of the ice the frozen continent contains - and thus, virtually every coastal city on Earth'. ${ }^{11}$

\section{Science hype}

Holthaus's use of the word 'hype' to refer to media coverage of this kind links his critique to a number of interrelated worries expressed by scientists, journalists, and other commentators about the way scientific findings are disseminated by the scientific press, reported upon by the media, and taken up by the scientific community. In what follows, I will refer to these worries under the general term 'science hype'.

Examples of science hype abound. In addition to the case described in the previous section, consider the following examples, taken from a workshop on hype in science held in Halifax, Nova Scotia in 2013: ${ }^{12}$

Liberation therapy: In 2008, a medical journal published a paper announcing a radical new treatment for Multiple Sclerosis (MS), a condition with no known cure. Although MS is generally thought to be a disease of the nervous system, 'liberation therapy' (LT), as the intervention was known, attempted to treat the condition by operating on the vascular systems of affected patients. Jock Murray, the former Dean of medicine at Dalhousie University, argues that the finding lacked support from properly conducted clinical trials, and that, as a result, the medical journal should not have published the paper. Murray alleges that the journal published the finding, in part, due to the possibility it constituted a breakthrough in treatment for an otherwise incurable disease. As Maderspacher puts in his summary of the presentation: 'So, here, [...] a medical journal, failed, allegedly because they deemed the importance of the issue more pressing than upholding the standards of clinical trials.' ${ }^{13}$ The finding was widely reported in the media, particularly in Canada, where MS patient groups demanded that LT treatments be covered by government health insurance while further tests were done. Eventually, several provincial governments complied with this request. Ultimately, however, the therapy was found to be ineffective. 
Epigenetics: Florian Maderspacher, the reviews editor for Current Biology, argues that findings in epigenetics, broadly understood as long-term, nongenetic effects on phenotype', ${ }^{14}$ are 'being hyped both inside and outside science for different reasons'. ${ }^{15}$ Outside science, the idea that there are nongenetic elements to heredity has been taken up as vindication for the idea that one's lifestyle will be passed on to future generations. Maderspacher illustrates this claim by citing a case where research in which a learned sensitivity to odour' was successfully transferred from one generation of mice to another was reported in the media as establishing that 'your fears can be transmitted to your grandchildren. ${ }^{16}$ On the other hand, within scientific circles, it is sometimes claimed that research of this kind heralds the emergence of a rival evolutionary paradigm to Darwinian theory. Although Maderspacher does not criticize the research itself, he does characterize such claims as hype. In his view, the findings of epigenetic research are neither as surprising, nor as important as they have been portrayed by scientists and the media.

The three cases exemplify a number of interesting interrelated phenomena. The Persian Gulf case features intense coverage of a single research finding in which an already alarming claim (that cities near the Persian Gulf will soon experience deadly heat events) has been exaggerated to fit an even more distressing narrative (climate change will create apocalyptic heat events, rendering the region uninhabitable). Along the way, the nuances of the finding (including the crucial information that the predicted heat events are avoidable) have been stripped away. Something similar seems to be happening in the news reports Maderspacher cites in his critique of epigenetics, where a technical advance in the understanding of heritability in mice is reported as establishing profound facts about human beings - a leap common in media coverage of medical research. There are other areas of concern: the liberation therapy case, for example, seems to involve the presence of both intense, largely uncritical media coverage, and a relaxing of scholarly publication norms. Furthermore, Maderspacher's critique of epigenetics research takes aim at both the nature of the media coverage and the amount of uptake the field has received within the scientific community. Abstracting from these examples, therefore, we can identify at least four varieties of science hype:

1) Exaggerated or careless reporting of carefully conducted scientific research. Exaggeration may come in the form of hyperbolic claims, or in the intensity of coverage. 
2) A failure to distinguish between peer-reviewed, statistically significant findings generated by well-accepted research methodologies and claims that lack such support but are phrased in superficially 'scientific' ways.

3) The publication of questionable research by otherwise reputable scientific journals because of its perceived importance.

4) The characterization of well-conducted, but prosaic, research as a revolutionary breakthrough.

The first two varieties of hype are features of the way scientific findings are presented in the non-scientific media, while the last two concern the uptake certain claims receive within the scientific community. Although I will mainly focus on media-driven forms of science hype in this chapter, it is worth reflecting on hype occurring within the scientific community. There are many factors giving rise to this kind of hype. Scientists are under pressure to publish original research to maintain funding and advance their careers. Such pressures may lead to the publication of research that otherwise would not be worth putting forward. In addition, demands that research be 'original', 'groundbreaking', or 'innovative' may affect both how scientists present their findings and what papers are published in scientific journals. That hype occurs within the scientific community suggests that science hype is not simply the product of the preoccupations and limitations of the non-scientific press, resulting from ignorance of scientific norms and procedure. Indeed, hype is a feature of all stages of the scientific dissemination process, from the initial circulation of preliminary findings within particular communities of scientists, to the process by which such findings come to be published in peer-reviewed journals, to the subsequent uptake these findings receive from the non-specialist press and the general public, and the way the findings are brought into political discourse by elected officials, political parties, and interest groups.

Turning our attention, therefore, to media-driven varieties of hype, it is possible to identify at least three worrisome consequences: ${ }^{17}$

1) Hype, especially when it takes the form of exaggerated or poorly contextualized coverage of scientific research findings, puts false information into the public sphere.

2) Hype has the potential to create false hope (of false despair) in the public at large, or in a particular subset of persons who may have a personal investment in the subject in question.

3) Finally, hype is worrisome because it threatens public trust in science and scientists. 
In what follows, I want to focus on the last of these claims - that science hype threatens public trust in science and the scientific community. It should be noted that the claim is ultimately an empirical one - albeit one that is quite difficult to investigate. ${ }^{18}$ Nevertheless, empirical investigation requires a definite sense of what the worry consists of and a more fully fleshed out account of how hype is supposed to threaten public trust. The rest of this chapter is aimed at providing such an account.

\section{Science hype and value judgements}

The use of the term 'hype' encodes a number of value judgements. For example, when Holthaus calls apocalyptic coverage of findings in climate science 'hype', he seems to mean that the scenarios described in coverage are so far removed from the import of the original research that they should not be taken seriously. Similarly, Murray's contention that much of the discourse surrounding liberation therapy consisted of hype puts forward the idea that the potential treatment had been taken far more seriously (both by the media and the scientific press) than it should have been, given the lack of scientific evidence supporting it. Finally, to claim that certain scientific findings should not be treated as major breakthroughs, no matter how well supported, is to judge them to be unworthy of the attention, investment, or uptake they have received.

For the most part, those taking an empirical or descriptive approach to hype have been reluctant to engage with such judgements. Peter Vasterman, for example, notes that definitions of hype that involve some reference to exaggerated media coverage encode at least two value judgements. For a given topic, one might judge that 1 ) it has received too much coverage (as in the liberation therapy case), or 2) judge that the media has exaggerated the 'real facts' of the story (as in the Persian Gulf example). Vasterman notes the first judgement is a subjective one, involving an assessment of what topics do or do not deserve attention. The second judgement, on the other hand, relies on there being an uncontroversial sense of what 'the real facts' of the story are. It is difficult to make an informed judgement in many cases of hype as the facts are either not yet known or partially constituted by discussions in the media. ${ }^{19}$ For these reasons, he concludes that 'a definition of media hype can only be based on the specific dynamic of a news wave, without an a priori denouncement of the phenomenon and excluding criteria like exaggeration and distortion'. ${ }^{20}$ In general, those providing accounts of media hype have followed Vasterman's lead in rejecting value-laden definitions of 
hype, preferring instead to look at the ways in which intense media coverage of certain issues and events comes about. ${ }^{21}$ While this work has improved understanding of how dynamics within the news media affect how stories are covered, the reluctance to engage with value judgements has meant that the implications of hype for epistemology, public policy, and practical reason are less well understood.

In general, philosophers are more comfortable engaging directly with value judgements in their work. However, as of this writing, there has been very little philosophical work done on the topic of hype. One of the few philosophers to address the topic, Uskali Mäki, does so by way of discussing disputes between traditional economists and scholars working in the emerging field of neuro-economics. ${ }^{22}$ In Mäki's view, traditional economists' use of 'hype' to describe the discourse surrounding neuro-economic research is rhetorically inflected. By using the term, traditional economists aim to signal that the norms applied and the methods used in the emerging sub-discipline are not the ones economists ought to use, and that the work is subsequently of little value. In other words, the use of 'hype' to describe neuro-economics research may be nothing more than a rhetorical move by traditional economists to distance themselves from a field with methods and assumptions of which they disapprove. ${ }^{23}$

Given Vasterman's and Mäki's concerns, one may wonder if the problem of science hype, as I have described it above, is intelligible. When Holthaus characterizes media coverage of findings in climate science as unduly apocalyptic, perhaps he is doing nothing more than claiming that the mainstream press and climate scientists have different standards for concepts such as 'uninhabitable'. His use of the term 'hype' to describe the coverage may simply be a means of signalling his disapproval of the version of the concept that appears in media reports. By looking at the issue in this way, the problem of science hype reduces to a dispute about what constitutes good and bad science.

I contend that a full account of science hype must engage in both the descriptive work of explaining how and why the news media come to cover particular stories in the way that they do, and the normative work of identifying and evaluating the value judgements in play when something is called hype. This is no mere academic dispute. Scientific findings, such as the one described in the Persian Gulf case, have important public policy implications. When such findings are apparently distorted in the course of being promoted, there is a need to pay attention to the way hype of this kind affects the ability of audiences to judge the value of information with which they have been presented. For this reason, I believe it is too hasty to 
dismiss concerns about science hype as mere ideological posturing. There is, then, a pressing need to think through the ways that facts and values interact in hype contexts.

\section{The Powers framework for media hype}

Devon Powers directly addresses the value problem in her framework for hype. ${ }^{24}$ Hype, on her account, is 'a state of anticipation generated through the circulation of promotion, resulting in a crisis of value'. ${ }^{25}$ For Powers, then, hype is less a feature of the way a particular message is constructed, or of the intentions of a particular speaker, than it is a feature of the way messages are received by audiences. In particular, hype can be identified with an attitude towards a topic that is conditioned by previous experience with promotional activity. This attitude is prospective (forward-looking), projecting a state of affairs that may or may not come to pass. In other words, promotional activity creates expectations which may or may not be met.

Powers argues that promotional activity should be understood quite broadly, as encompassing not only traditional advertising and public relations work, but also media reports, social media posts, and even face-to-face conversations. Importantly, Powers argues that promotional activity must 'circulate' in order to produce hype. As Powers puts it: 'hype becomes - as ads and news stories accumulate; as branding campaigns progress; and as various kinds of audiences read, consume, and debate'. ${ }^{26}$ The idea is that promotional acts in different domains interact with each other, intensifying and varying the message received by particular audiences.

Finally, Powers notes that hype produces a 'crisis of value'. The crisis occurs as the expectations set by circulating promotional activity fail to be borne out by subsequent events. Such failures may occur because one's expectations have been set too high, but they can also occur if one's expectations have been set too low (as might happen if one holds back from engaging with something because of previous experience with excessive promotion). Because the process is likely to repeat itself many times in one's life, one may come to find it difficult to make value judgements about topics that have been the subject of intense, circulating promotion. In short, the state of anticipation created by circulating promotion makes it difficult to identify the features that might be helpful in making such judgements. For Powers, the capacity to produce a crisis of value is what distinguishes hype from other, less negatively-valanced products of promotion such as buzz. 
This dynamic is perhaps best understood in the context of traditional advertising. In such cases, the value in crisis is monetary - what a given product is (or ought to be) worth to a given person. When a product is the subject of promotion for a long period of time, one's expectations may be raised such that one is disposed to overvalue it - making one willing to pay far more for it than one might have done in other circumstances. On the other hand, especially if one has been through the process before, one may come to undervalue products that receive heavy promotion. Indeed, by repeatedly and systematically affecting one's expectations, promotion of this kind may make it difficult even to determine on what basis such judgements of value should be made.

What values does science hype put into crisis? Although Powers does not explicitly discuss the topic in her paper, she does identify credibility as a value that can be thrown into crisis. The value of credibility is particularly germane to epistemic contexts, such as those that govern the assessment of scientific claims. If hype is able to put judgements of credibility into crisis, then it can create a situation in which individuals are uncertain of who and what they ought to believe. In such a state of confusion, such individuals may be led to fall back on previously held beliefs, evocative narratives, or comforting biases instead of well-justified scientific evidence. Furthermore, some parties might take advantage of this confusion to push their agendas. A context in which credibility is in crisis is one in which claims that it is still an open question whether anthropogenic climate change is really happening are more plausible than they otherwise might be. ${ }^{27}$ It is in this sense, perhaps, that hype may serve to undermine public trust in science. ${ }^{28}$

Let us now apply Powers' framework to the Persian Gulf case study. First, Pal and Eltahir put forward their account of their research, first in an academic paper, and, later, in an MIT press release. The information in the press release was then re-reported and re-contextualized as media outlets each put out their own version of the story. For example, the Washington Post framed the story of a changing climate in the Persian Gulf in terms of what such changes would mean for its (presumably North American) readers, while the Discovery Channel's post placed the finding within an apocalyptic narrative. As the message circulated - as each successive news article was posted to the web, reposted, and commented upon on social media and discussed by different audiences in different contexts, the story was re-contextualized even further. Among these re-contextualizations was Holthaus' post, which attempted to steer the story back to something that more closely resembled the original account. Eventually, the wave died down as writers and audiences moved on to other stories, leaving different 
audiences with different expectations depending on the contexts in which they had encountered the story. Some may coalesce around the dominant apocalyptic narrative, while others might refuse to engage with the story altogether. Still others, noting the variety of conflicting accounts, may not know what to do or what to believe. Because hype events are quite common (for example, only two weeks separated Holthaus' post on the Persian Gulf finding and a similar 'debunking' post concerning coverage of melting Antarctic glaciers), it may become difficult for audiences to determine what messages they should trust. Furthermore, because these messages come from a wide variety of sources, audiences may find it difficult to decide who is a trustworthy source for such information in the future.

\section{Combatting science hype}

Now that we have sketched an outline of science hype, one may well wonder how it can be combatted. Commentators have proposed a number of remedies. One option is the notion of 'Post-Publication Peer Review' (PPPR), where knowledgeable commentators attempt to push back against exaggerated or poorly researched science by writing blog posts and essays accessible to the general public. ${ }^{29}$ Holthaus' post on the Persian Gulf case is an example of such a strategy in action. Another proposal, aimed at curtailing hype within the scientific community, is to enforce stricter standards for scientific publication. At one extreme is the suggestion, related in Maderspacher, that scientific journals be banned from featuring glossy covers with striking graphics or photography. Finally, most discussions of the topic include a call to increase scientific literacy among journalists and the general public.

The Powers framework for hype can help in understanding why these proposed remedies, while not without merit, are unlikely to be effective at combatting science hype. Firstly, most of the remedies rely on an unstated faith that 'the truth will out' - that once the actual facts about a given subject are put into the public sphere, the hype surrounding it will dissipate. This certainly seems to be the assumption underlying the notion of PPPR. However, this assumption seems too optimistic, since it requires both that the corrective reach the affected audience and that the audience recognize the corrective as authoritative. The former cannot be guaranteed, while the latter may be difficult if the audience finds itself in the grip of the crisis of value, and thus finds it difficult to evaluate the credibility and value of the information provided by a given source. This suggests that methods such 
as PPPR are not likely to be effective at combatting the general narrative that hype has built up around a given subject.

Secondly, many of the remedies rely on adopting more austere norms for scientific communication, such as banning glossy covers for science journals or videos like the ones that accompanied the MIT press release promoting Pal and Eltahir's research. Doing so would restrict access to the information in the articles to those qualified to read it, and so would prevent the kind of media coverage that exaggerates the findings of carefully conducted research. However, such an approach would seem to be at cross-purposes with the notion that science should have a bearing on public policy. Indeed, when one's research concerns something as wide-ranging as global climate change, it is unclear what the benefit of keeping this information locked up would be. A solution that denies the need for scientific findings to be publicized to the general public seems no solution at all. Although some degree of reticence is clearly necessary in science communication, this is not a value to be maximized.

Finally, although greater scientific literacy on the part of the general public, or at the very least, on the part of journalists, would certainly ensure more careful presentation of scientific findings (and would allow those findings to be better evaluated by particular audiences), there are two challenges that need to be addressed. The first challenge is that hype appears to be as much a problem within the scientific community as it is outside of it. If, as has been suggested, prestigious journals are susceptible to lowering thresholds for publication when faced with provocative or potentially groundbreaking research, it is not clear that an increased understanding of scientific norms and methods will be sufficient to prevent the spread of science hype.

The second challenge is related to the first: given increased scientific specialization, the background required to judge the importance and value of particular scientific findings is quite vast. Given that public policy may be affected by scientific findings in a wide-range of disciplines and subdisciplines, it seems unlikely that a sufficient level of literacy could be achieved by a single individual, let alone by the general public. ${ }^{30}$ For example, the major finding of the research in the Persian Gulf case study hinges on an understanding of a quite technical definition of human survivability. While increased literacy may help with the public's understanding of basic scientific concepts and methodology, it will not do much to help audiences evaluate the content of specific scientific claims reported in the media.

In what remains of this chapter, I will attempt to sketch a couple of potentially more fruitful alternatives. One approach to addressing mediadriven science hype would be to pair increased scientific literacy with 
increased media literacy. If audiences had a better understanding of how the media comes to report on different topics and how they come to frame present information in the way that they do, they may be less susceptible to the crises produced by media-driven hype. More generally, defusing mediadriven science hype may require the development of new habits of mind. In earlier work, I suggested that, in contexts of hype, one should aim towards a virtue of proportionality, that is to say keeping new claims in the proper perspective. ${ }^{31}$ The virtue can be thought of as existing midway between two vices - credulousness and cynicism. A credulous person believes everything she hears in a hype context, while a cynical person rejects it. Both vices are dangerous ones. A credulous agent risks disappointment when her expectations are not met. The cynical agent, on the other hand, risks missing out on something valuable or important. Developing a sense of proportion requires looking beyond one's immediate experience of a subject and asking questions about the circumstances in which the discourse surrounding that subject has been produced.

Another means of combatting science hype may be found in the tendency of hype to follow pre-existing narratives. For example, the hype surrounding $\mathrm{Pal}$ and Eltahir's research into the changing climate around the Persian Gulf seemed to feed on already existing narratives of apocalypse and disaster. These narratives, which form the basis of the plots of disaster movies such as Roland Emerich's The day after tomorrow, present disasters as beyond the human ability to prevent or mitigate - it is almost as though the disaster is divinely ordained and the best individual humans can hope for is to somehow survive. As a result, coverage of Pal and Eltahir's work tended to downplay the notion that their predicted disasters were avoidable ones. Perhaps if there existed, in popular circulation, narratives in which coordinated action served to prevent potential disaster, the coverage might be pushed in more positive direction.

\section{Notes}

1. Pal \& Eltahir (2015).

2. Chandler (26 October 2015).

3. Ibid.

4. Holthaus (27 October 2015).

5. Schwartz (26 October 2015).

6. Warrick (28 October 2015).

7. Worland (26 October 2015). 
8. The website has since been rebranded as 'Seeker.com'

9. Niler (26 October 2015).

10. Holthaus (27 October 2015).

11. Holthaus (14 October 2015).

12. The event was organized by Ford Doolittle, a professor of biology at Dalhousie University, under the auspices of the Situating Science research group. Video of the presentations is available at Situating Science (2014). Conference presentations are summarized in Maderspacher (2014).

13. Maderspacher (2014), p. R301.

14. Ibid., p. R299.

15. Ibid., p. R299-R300.

16. Ibid., p. R3oo.

17. Hype within the scientific community also has potentially worrisome implications. In particular, it has the potential to skew decisions about what projects receive funding, attention, and human investment.

18. Master and Resnik (2011) make this point in their review of empirical work on the effect of hype about biotechnology on the expectations of particular patient groups. They also go into detail about the difficulties of assessing the effect of science hype on the general public.

19. Vasterman, in comments on an earlier draft of this chapter, points out that media coverage of scientific findings is something of an exception to this principle, since in such cases we can compare claims made in media reports to the findings contained in the original study. However, the specialized knowledge required to understand the implications of such research may make it difficult for non-scientific audiences to make such a comparison. For example, in the Persian Gulf example, the problem seems to have arisen, at least in part, due to the ambiguity of concepts such as 'survivability and 'uninhabitable'. Although Pal and Eltahir used technical definitions for such terms in their research, reporters and other non-specialist writers applied them more broadly. This ambiguity makes it difficult to establish just what interpretation of the term should be the subject of concern.

20. Vasterman (2005), p. 512.

21. Some writers go even further than Vasterman. For example, while Vasterman draws a distinction between media-driven and organically unfolding news stories, Wien and Elmelund-Præstekær (2009) reject such a distinction, in part because it relies on access to facts that one cannot always expect to have (namely, whether or not someone has been manipulating the story at some level).

22. Mäki (2010).

23. I discuss rhetorical manoeuvres of this kind in more detail in Auch (2013).

24. Powers (2012).

25. Ibid., p. 863 .

26. Ibid.

27. The crisis of credibility can be connected with concerns that post-modern approaches to truth that see it as socially-constructed can be co-opted 
by the same forces that such approaches were developed to critique. See Latour (2004). Thank you to Peter Vasterman for raising this point.

28. This process also serves to undermine trust in the news media. The problem of science hype is thus not merely a concern for scientists alone. Thank you to Peter Vasterman for this observation.

29. PPPR was championed by Rosie Redfield at the Halifax conference on science hype. See Maderspacher (2014).

30. Master \& Resnik (2011) note that empirical work on hype and biotechnology suggests that specific populations (for example, those affected by a particular disease or medical condition) do not show any loss of trust in science when confronted with hype about technology and treatment related to their circumstances. However, it is unclear whether the implications of these results can be extended to more diverse and less informed audiences.

31. Auch (2013).

\section{References}

Auch, Adam (2013). 'Virtuous argumentation and the challenges of hype'. OSSA Conference Archive. Paper 12. Available at: http://scholar.uwindsor.ca/ossaarchive/ OSSA10/papersandcommentaries/12.

Chandler, David L. (2015). 'Study: Persian Gulf could experience deadly heat'. MIT News, 26 October. Available at: from http://news.mit.edu/2015/ study-persian-gulf-deadly-heat-1026.

Holthaus, Eric (2015). 'Yes, Antarctic ice is melting, but there's a bright side'. Slate, (14 October). Available at: http://www.slate.com/blogs/future_tense/2015/10/14/ antarctica_ice_shelf_collapse_is_a_climate_opportunity.html.

Holthaus, Eric (2015) 'No, climate change won't make the Persian Gulf 'uninhabitable". Slate, (27 October). Available at: http://www.slate.com/blogs/ future_tense/2015/10/27/climate_change_heat_waves_won_t_make_persian_gulf_uninhabitable.html.

Latour, Bruno (2004). 'Why has critique run out of steam? From matters of fact to matters of concern'. Critical Inquiry, 30 (2): 225-248.

Maderspacher, Florian (2014). 'Hype in Halifax'. Current Biology, 24 (8): R298-R3o1.

Mäki, Uskali (2010). 'When economics meets neuroscience: Hype and hope'.Journal of Economic Methodology, 17 (2): 107-117.

Master, Zubin \& David B. Resnik (2013). 'Hype and public trust in science'. Science and Engineering Ethics, 19 (2): 321-335.

Niler, Eric (2015). 'Burning hell coming for Mideast deserts'. Seeker (formerly Discovery channel), 26 October. Available at: http://www.seeker.com/burninghell-coming-for-mideast-deserts-1770385216.html. 
Pal, Jeremy \& Eltahir Elfatih (2015). 'Future temperature in southwest Asia projected to exceed a threshold for human adaptability'. Nature Climate Change 6: 197-200.

Powers, Devon (2012). 'Notes on hype'. International Journal of Communication 6: $857-873$.

Situating Science (2014). 'Hype in science: How can respectable journals publish such c**p?' YouTube. Available at: https://www.youtube.com/ watch?v=nhnA4w2sQvw.

Schwartz, John (2015). 'Deadly heat is forecast in Persian Gulfby 210o'. The New York Times, 26 October. Available at: http://www.nytimes.com/2015/10/27/science/ intolerable-heat-may-hit-the-middle-east-by-the-end-of-the-century.html.

Vasterman, Peter (2005). 'Media-hype. Self-reinforcing news waves, journalistic standards and the construction of social problems'. European Journal of Communication 20 (4): 508-530.

Warrick, Joby (2015). 'Persian Gulf may be too hot for human survival by 209o. Here's what this means for your city'. The Washington Post, 28 October. Available at: https:/www.washingtonpost.com/news/energy-environment/wp/2015/10/26/ climate-change-could-soon-push-persian-gulf-temperatures-to-lethalextremes-report-warns/.

Wien, Charlotte \& Christian Elmelund-Præstekær (2009). 'An anatomy of media hypes: Developing a model for the dynamics and structure of intense media coverage of single issues'. European Journal of Communication, 24 (2): 183-201.

Worland, Justin (2015). 'These cities may soon be uninhabitable thanks to climate change'. Time, 26 October. Available at: http://time.com/4087092/ climate-change-heat-wave/.

\section{About the author}

Adam Auch received a PhD in philosophy from Dalhousie University in 2012. Since then, he has taught courses in the philosophy departments at Dalhousie, Saint Mary's University, and Mount Allison University. Currently, he works as a writing advisor for the Dalhousie University Writing Centre. His research is focused on the norms of language use and communication and their implications for the dissemination of knowledge. 
